\title{
Unification of Sinonasal Anatomical Terminology
}

\author{
Richard Louis Voegels ${ }^{1}$ Nelson Almeida Davila Melo ${ }^{1}$ \\ ${ }^{1}$ Department of Otolaryngology, University of Sao Paulo, Sao Paulo, \\ Sao Paulo, Brazil \\ Int Arch Otorhinolaryngol 2016;20:1.
}

The advent of endoscopy and computed tomography at the beginning of the 1980s brought to rhinology a revival of anatomy and physiology study. In 1994, the International Conference of Sinus Disease was conceived because the official "Terminologia Anatomica"1 had little information on the detailed sinonasal anatomy. In addition, there was a lack of uniformity of terminology and definitions. After 20 years, a new conference has been held.

The need to use the same terminology led to the publication by the European Society of Rhinology of the "European Position Paper on the Anatomical Terminology of the Internal Nose and Paranasal Sinuses," that can be accessed freely at www.rhinologyjournal.com. Professor Valerie Lund et $\mathrm{al}^{2}$ wrote this document reviewing the anatomical terms, comparing to the "Terminology Anatomica" official order to define the structures without eponyms, while respecting the embryological development and especially universalizing and simplifying the terms.

A must-read! The text's purpose lies beyond the review of anatomical terminology to universalize the language used to refer to structures of the nasal and paranasal cavities. Information about the anatomy, based on extensive review of the

\author{
Thiago Bezerra ${ }^{1}$
}

Address for correspondence Richard Louis Voegels, MD, PhD, Department of Otorhinolaryngology and Ophthalmology, Av. Dr. Enéas de Carvalho Aguiar, 255-6 andar-sala 6167, São Paulo, São Paulo 05403000, Brazil (e-mail: rvoegels@gmail.com).

current literature, is arranged in just over 50 pages, which are direct and to the point. The publication may be pleasant reading for learners and teachers of rhinology.

This text can be a starting point and enables searching the universal terminology used in Brazil, seeking to converge with this new European proposal for a nomenclature to help us communicate with our peers in Brazil and the rest of the world. The original text of the European Society of Rhinology provides English terms that avoided the use of Latin, and thus fall beyond several national personal translations. It would be admirable if we created our own crosscultural adaptation of this new suggested anatomical terminology.

\section{References}

1 FIPAT, Federative International Programme on Anatomical Terminologies. Terminologia Anatomica - International Anatomical Terminology. New York: Thieme Medical Publishers; 2011

2 Lund VJ, Stammberger H, Fokkens WJ. European Position Paper on the Anatomical Terminology of the Internal Nose and Paranasal Sinuses. Rhinology 2014;21;(Suppl.):1-34 received

April 2, 2015

accepted

April 18, 2015

published online

July 29, 2015
DOI http://dx.doi.org/

10.1055/s-0035-1554726. ISSN 1809-9777.
Copyright $(2016$ by Thieme Publicações License terms

Ltda, Rio de Janeiro, Brazil 